\title{
How Do We Thank Thee? Let Us (Try to) Count the Ways
}

\author{
Leigh E. Rich
}

Received: 5 January 2015 / Accepted: 21 January 2015 /Published online: 21 February 2015

(C) Journal of Bioethical Inquiry Pty Ltd. 2015

"Beggar that I am, I am even poor in thanks."

- Hamlet, II.ii.272

About four years ago, we at the Journal of Bioethical Inquiry realized the thankless don't get thanked enough. It is, of course, built into the very definition of the category. And, yet, all those who fit this bill ceaselessly beat on-be it reviewing articles namelessly and without reward; offering guidance on papers and protocols; managing and editing manuscripts; taking on the tiring role of taskmaster; processing, paginating, promoting, and publishing; and generally engaging excitedly in the scholarly pursuit.

We thus began an annual tradition of taking a few paragraphs every year in an attempt to thank our peer reviewers by name and all those who make the Journal of Bioethical Inquiry possible. We know that it is not much and that we are "even poor in our thanks." As Colley Cibber (though not very successfully) once pointed out, "[w]ords are but empty thanks" (Woman's Wit, V.393) and offer little real compensation and recognition. Of course, we also know that everyone involved with the $J B I$ assumes such responsibilities out of other, greater intentions, making the sharing of one's expertise that much more honorable.

Over the past year, several members of the $J B I$ community have retired, at least from the journal, in order to

L. E. Rich $(\bowtie)$

Department of Health Sciences (Public Health), Armstrong

State University, 11935 Abercorn Street, University Hall

154F, Savannah, GA 31419, USA

e-mail: leigh.rich@armstrong.edu focus on different areas and contribute to other worthy goals. We cannot offer enough thanks to Margaret Otlowski, who served on our Editorial Board; Steven Wainwright, associate editor of Sociology and Bioethics; Elizabeth Peter, associate editor of Nursing and guest editor of a recent symposium on "Moral Distress"; and especially Cameron Stewart, associate editor of Law, a founding member of the journal, and a key contributor to the initial and continuing development of the entire $J B I$ project.

We also have been incredibly fortunate to welcome new members to the JBI. Our International Advisory Board has expanded to include Amnon Carmi, UNESCO Chair of Bioethics, University of Haifa, Israel; Zabidi Hussin, Universiti Sains Malaysia; Sastrowijoto Soenarto, University of Gadjah Mada, Indonesia; and Duujian Tsai, Taipei Medical University, Taiwan.

Several new associate editors have joined the ranks as well and have been hard at work from day one: in Cross-Cultural Bioethics, Peter Omonzejele, University of Benin, Nigeria; in Globalization, Ted Schrecker, Durham University; in Nursing Ethics, Sarah Breier, University of Missouri-Columbia, and Felicia Stokes, District of Columbia Board of Nursing; in Public Bioethics, Lisa M. Lee of the U.S. Presidential Commission for the Study of Bioethical Issues; and in Science and Genetics, Ainsley Newson, University of Sydney, and Robin Pierce, Harvard Law School. (Other associate editors who came on board a few years back but were never formally welcomed include Gail Van Norman, University of Washington, in Clinical Ethics and Jan Deckers, University of Newcastle, Wendy Lipworth, University 
of Sydney, and Sean M. Philpott, Union Graduate College, in Research Ethics. Jon F. Merz, University of Pennsylvania, also has been serving the $J B I$ as Ombudsman since 2012.)

Moreover, the journal has grown with the addition of a second consulting editor, David Shaw, Universität Basel, Switzerland - who attends weekly and monthly conference calls in the middle of the night and has proven so indispensable we are not certain how we once survived - as well as two editorial assistants: Sheila Pham, University of Sydney, focusing on Communication and Engagement and Emma Sacks, Columbia University, focusing on Global Health.

We couldn't accomplish any of this, of course, without our countless guest editors, our copy editors Pia Smith and Bronwen Morrell, and our Springer partners. Our publishing editor, Floor Oosting, is diligent and a delight, even traveling across the globe every year to meet with us in person. Christopher Wilby, our Springer publishing assistant, is equally skilled and charming and never gets ruffled despite periodic delays on our end. We offer heartfelt thanks to Hansel Camero, publishing project officer; Carmina Cayago, journal editorial office assistant; and especially Jan deVries, our longtime production editor, who with professionalism, warmth, and a great sense of humor has accommodated and worked alongside us for many years. We also warmly welcome Catherine Murphy into this role, who already has taken over the reins without so much as a bump in the ride.

Last in line, though not in esteem, are all those who have long served the $J B I$ - our vital associate editors for various portfolios, our international associate editors in Law, and members of our Editorial Board and International Advisory Board whom we haven't named hereas well as Paul Komesaroff, chair of our Editorial Board, who keeps us rowing together and the entire boat afloat; Ian Kerridge, an essential member of our Executive Committee (and trickster in the most beloved sense of the word), who repeatedly picks up everyone's slack without complaint; and Michael Ashby, consulting editor and a brilliant, inspiring, and endearing partner-incrime.

Not enough can be said of Bronwen Morrell, the $J B I$ 's longstanding (and likely long-suffering!) managing editor, who never flags in her talent, skill, intellect, wit, and simultaneous ability to herd cats and keep multiple spinning plates from crashing to the floor and thus crushing the entire enterprise. The vocation of a managing editor is much like housework: an ongoing, unappreciated but essential round of chores that nobody notices unless you don't do it. Nearly all of her (endless) work goes unrecognized, but every aspect of every issue - and some even more than others - are held together by the threads she has sewn.

Thank you all for your continuing efforts and for making the Journal of Bioethical Inquiry a community one cannot help but be honored and grateful (and perhaps a little amazed!) to be a part of.

Below, please find a special round of thanks to all who have served as a peer reviewer for one or more articles over the past year, from January 2014 to January 2015.

Abdulaziz Sachedina

Adam Feltz

Alexander Lautensach

Alexis Shotwell

Alison K Thompson

Allan Stirling

Andrea Frolic

Andrew Courtwright

Andrew Watkins

Anna Gotlib

Anna Smajdor

Annette Opitz-Welke

Anvar Velji

Ariel Eytan

Ben Gray

Ben Hippen

Benjamin Herreros

Brandon Brown

Brian Callender

Brian Seavey

Bridget Haire

Britt Elsa Johnson

Cameron Ellis

Carolyn McLeod

Carwyn Hooper

Catherine Belling

Charles Douglas

Christopher James Ryan

Christopher Mayes

Christopher Reynolds

Claire Hooker

Clara Burbano Herrera

Colin Thomson

Colleen Cartwright

Craig Fry 
Daniel Fu-Chang Tsai

Daniel Young

Daniela Andres

Daniela Cutas

David Isaacs

David Neil

David Randall Gaertner

David Serlin

Diana Tietjens Meyers

Diane P. Freedman

Diane Price Herndl

Donald Cole

Eleanor Milligan

Elizabeth Wager

Emily Waples

Emma Kivisild

Engwa Azeh Godwill

Eric Racine

Erin Koch

Eva Kittay

Evie Kendall

Ezio Di Nucci

Fabrice Jotterand

Fern Brunger

Floris van den Berg

Gabriel Bosslet

Geert Robaeys

Geoffrey Miller

Georgiann Davis

Gina M. Altavilla

Goldberg Daniel

Heidi Ewen

Hrothgar Cynric Algarín Sidaway

Israel Berger

Jan Angus

Jane Schultz

Jason L. Schwartz

Jay Clayton

Jeanne Daly

Jeff Jacobs

Jeffrey Janis

Jenni Millbank

Jennifer Parks

Jeremy Wickins

Jerome Endrass

Jill Gordon

Johanna Rian

John Bartlett

John Hoberman
John Wiltshire

John Z. Sadler

Jonny Anomaly

Joseph F. Kras

Joseph Shaw

Juha Raikka

Julie Elman

Julie Letts

Julie Park

Justin T. Denholm

Justine Strand

Jyotsna Gupta

Katrien Devolder

Kayte Spector-Bagdady

Kearsley Stewart

Kelly Anderson

Ken Kipnis

Kenneth Robert Abbey

Kevin James Goodwin

Kim Lutzen

Kimberly Leighton

Kristina Orfali

L. Syd M. Johnson

Licia Carlson

Lilon Bandler

Linnea Laestadius

Lisa Cartwright

Lisa Diedrich

Lucas França Garcia

Luke Strongman

Lynn Gillam

Lynn Woodward

Lysa Mackeen

Mahala Stripling

Malcolm Keith Smith

Malika Sharma

Marc Epprecht

Marie Bismark

Marie Edwards

Mark Cherry

Mark Munsterhjelm

Marta Elena Losa Iglesias

Matti Hayry

Melissa McCullough

Meredith Blake

Merle Spriggs

Merrilyn Walton

Michael Atkinson

Michael David Dahnke 
Michael Kekewich

Michael Levy

Michael McDonald

Michael Souter

Michael Weingarten

Michelle Taylor-Sands

Mitchell Lawlor

Morven Shearer

Nanya Philipsen

Neil Arya

Neil Francis

Neil Price

Nicolas Rasmussen

Otte Brosjo

Pamela Teaster

Patrick Blessinger

Paul Baines

Paul Biegler

Pauline Lane

Pawan Singh

Peter Nichols

Peter Saul

Pieter Bonte

Ramzi Fawaz

Rebecca Reviere

Reinhard Dettmeyer

Renaud F. Boulanger

Renee Boss

R.J. Richards

Robert Darby
Robert Orr

Ron Paterson

Ronald Aday

Samuel Taylor-Alexander

Sandra Bradley

Sascha Callaghan

Shahram Ahmadi Nasab Emran

Shih-Ning Then

Silvia Camporesi

Simon Woods

Stanley Rosenbaum

Stephen John Genuis

Steve Shen

Steven Jackson

Steven Kenyon Ault

Sumedha Ariely

Susan MacCallum

Susan Palmer

Susanna Taraschi

Susannah Cornwall

Thaddeus Mason Pope

Therese Jones

Thomas David Harter

Trevor Gordon Stammers

Trish Bartlett

Ueli Hostettler

Vardit Ravitsky

Victoria Kain

Wei Ouyang

Xavier Livermon 